\title{
PORTFOLIO
}

\section{Creative Community Development. From urban design studio to international collaborative workshop}

\author{
Jarunee Pimonsathean \\ Thammasat University, Thailand \\ Faculty of Architecture and Planning, Urban Design and Development International Programme \\ jaepim@windowslive.com
}

Creative Community Development Workshop is a collaborative programme initiated from the two tiers of academic endeavours to achieve people's involvement to foster cities in sustainable manner. The first tier is a regular programme from a studio subject in Urban Design and Development International Programme, Faculty of Architecture and Planning at Thammasat University, UD326 Urban Regeneration, aiming to enabling students to identify and investigate a 'dead' or 'lost' urban area and create a design programme to regenerate and transform the urban environment. The studio working approach is conducted by working with the stakeholders to derive collective information, ideas and experiences for design processes and final proposal, by which must address the multiple needs of a variety of stakeholders, and is expected to be relevant to a particular neighbourhood whilst considering the impact of the regeneration on the larger city. The second tier is an annual international academic consortium event, established since 2009 upon the initiative of the Yokohama City University (YCU) called, "the International Academic Consortium for Sustainable Cities (IACSC)", as a result of YCU's participation as coordinator of the meeting session entitled "Cities and Universities - Towards Collaboration for Sustainable Cities" at the conference of CITYNET, held on 9 September 2009 in Yokohama City, Japan. Focusing on urban planning, public health and environment as the major components of cities, the consortium endeavours to develop cooperation, foster dialogues and discussions, encourage sharing of information and resources and promote networking mainly in Asia on research and collaborative activities between academic and research institutions, and establish and strengthen the linkage between universities and the cities where they belong towards capacity building for a sustainable society. Since 2010 the consortium has to date conducted 8 general assemblies and symposiums, annually rotated hosted by 6 networking universities from Japan, Malaysia, Thailand, Philippines, Vietnam and South Korea where provide teaching courses in planning, urban design, built environment and architecture. The networking universities have worked closely to compile examples of case studies with supports for the collaboration by cities, international organisations, development agencies and NGOs.'

\footnotetext{
' Office of International Affairs, Thammasat University (2017). 'About IACSC - IACSC 2017 in Bangkok', in http://www.iacsc2017.com/about-us/, 28 December 2017, 14.10 hrs; Yokohama City University (2017).
} 
The workshop in 2017 on Creative Community Development was an activity under the $8^{\text {th }}$ IACSC Symposium on "Well-being of Sustainable Living in Aging Population Era" which was hosted by Thammasat University at Rangsit Campus. The workshop was hosted by Urban Design and Development International Programme (UDDI), between 5-I I September 2017 at the Faculty of Architecture and Planning and on-site study area in Suan
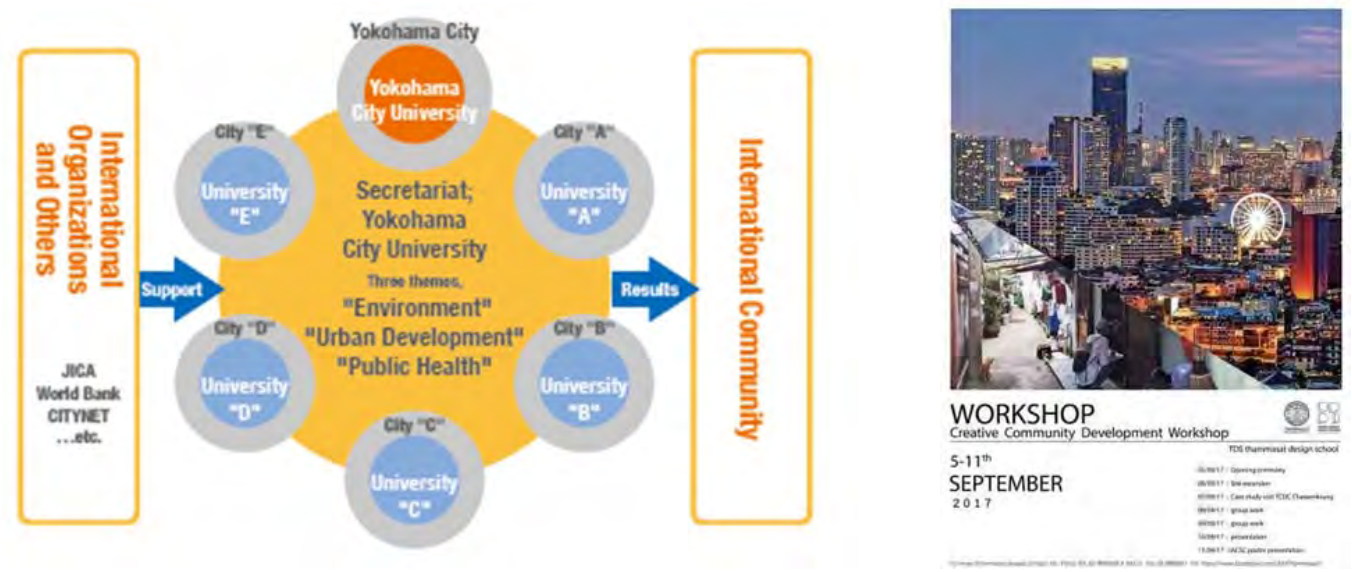

Fig I (left). The structure of the International Academic Consortium for Sustainable Cities (IACSC) Figure 2 (right) The Creative Community Development Workshop poster Source: IACSC, 2017

Yai Bang Kwang, Bang Kho Laem District, Bangkok, and conducted in a week session on the preliminary stage of community development study and regeneration proposal for the Urban Regeneration studio, led by the unit lecturers and studio supervisors Associate Professor Dr Yongtanit Pimonsathean, Ms Jarunee Pimonsathean and Ms Hansa Srilertchaipanij (also as the unit coordinator).

The workshop participants included 60 students, 10 instructors and 2 research assistants from four leading universities in Asia: Department of Urban and Community Planning, Faculty of Global, Regional and Urban Studies, Yokohama City University (YCU), Japan, under the supervision of Prof Dr Nobuharu Suzuki, Prof Naoyuki Kuniyoshi, Assoc Prof Dr Masahiko Nakanishi and Assoc Prof Dr Mariko Fujioka; Division of Architecture and Urban Design, College of Urban Sciences, Incheon National University (INU), South Karea, Ass Prof Hwan Yong, Kim, PhD; School of Housing, Building and Planning, Universiti Sains Malaysia (USM), Malaysia, Dr Diana binti Mohamad; and, Urban Design and Development International Programme, Thammasat University, Thailand, all the UD326 studio course supervisors and the visiting professor to UDDI Dr Mirko Guaralda, the senior lecturer from Faculty of Creative Industries, School of Design, Queensland University of Technology (QUT) in Brisbane, Australia, with the valued support from the workshop assistants Mr Jin Ho, Kim (INU) and Mr Taizo Kondo (YCU). It was apparently

'The International Academic Consortium for Sustainable Cities (IACSC)', in https://www.yokohamacu.ac.jp/en/global/iacsc/, 28 December 2017, $14.10 \mathrm{hrs.}$

I I 2 | The Journal of Public Space, 2(4), 20I7| ISSN 2206-9658

(C) Queensland University of Technology 
made a time for a biggest number of workshop participants in academia in this region so far.

The aims of the workshop are to promote a mutual understanding among the international students, to enhance the students' ability to propose planning scheme proposal in communicable manner, and, to give an opportunity for students to work with and contribute to the local community the community development ideas towards livability and sustainability.

Since the quality of its process that can improve quality of life of dilapidated urban areas through holistic approach, the 'urban regeneration' model was introduced to be applied for the workshop exercise to a city area where decayed conditions are found whilst rapid urbanisation has been transforming its surrounding environment. And for confidentiality, the exercise area has to be possibly accessible for the visits and data collection by approval of the landowners' consent. Finally, with the agreement among all the collaborative university instructors, an area close to a central business district in southern part of Bangkok was selected.

\section{Background and history of land development of the study area ${ }^{2}$}

The study area is called, "Suan Yai Bang Khwang", located in Bang Kho Laem District, one of the fifty districts in Bangkok. Covering 6I.5 hectares kilometers and having density 164 persons/hectare, the area is administered under Bang Kho Laem District Office authority, by ten communities are registered with the local government to gain supports and budget for their community development. The land tenures in the area are rent from the Crown Property Bureau, the quasi-government agency responsible for managing the property of the crown of the Kingdom of Thailand.

The number of population in the area is between 25,000-30,000, having been mix of ethnicity since the communities established i.e. Thai Buddhist, Thai Muslims, and Chinese, and later in recent decades Laos, Myanmars, Cambodians, etc. earning livelihoods as petty traders, day laborers, company employees, etc. Some of them have participated in the community organisation activities, mostly in the pursuit of maintaining their ethnic cultures and societies, performing through religious and cultural places e.g. mosques, shrines of the city-god, community centres, etc.

The area was first developed in $18^{\text {th }}$ century as a large orchard field. In $19^{\text {th }}$ century the waterfront development was introduced into the nearby area, created warehouses, saw mills, rice mills and lumber settlements, and hence marked the impact on the development of the area mixing with communities, including Suan Yai Bang Khwang. In the 1950s the land was transferred to the Crown Property Bureau; subsequently, urban housing spreaded in the area over the 1960s-1970s, making communities since then. Recently the surrounding areas were dramatically developed due to the launch of the expressway project operational to the district and nearby, and the opening of the largescale development the Asiatique the Riverfront and the waterfront high-rises.

\footnotetext{
2 Pimonsathean, Yongtanit (2017). "Urban Regeneration (UR) in Bangkok”, the handout of UD326 Urban Regeneration, session week 3, Monday 4 September 2017.
} 

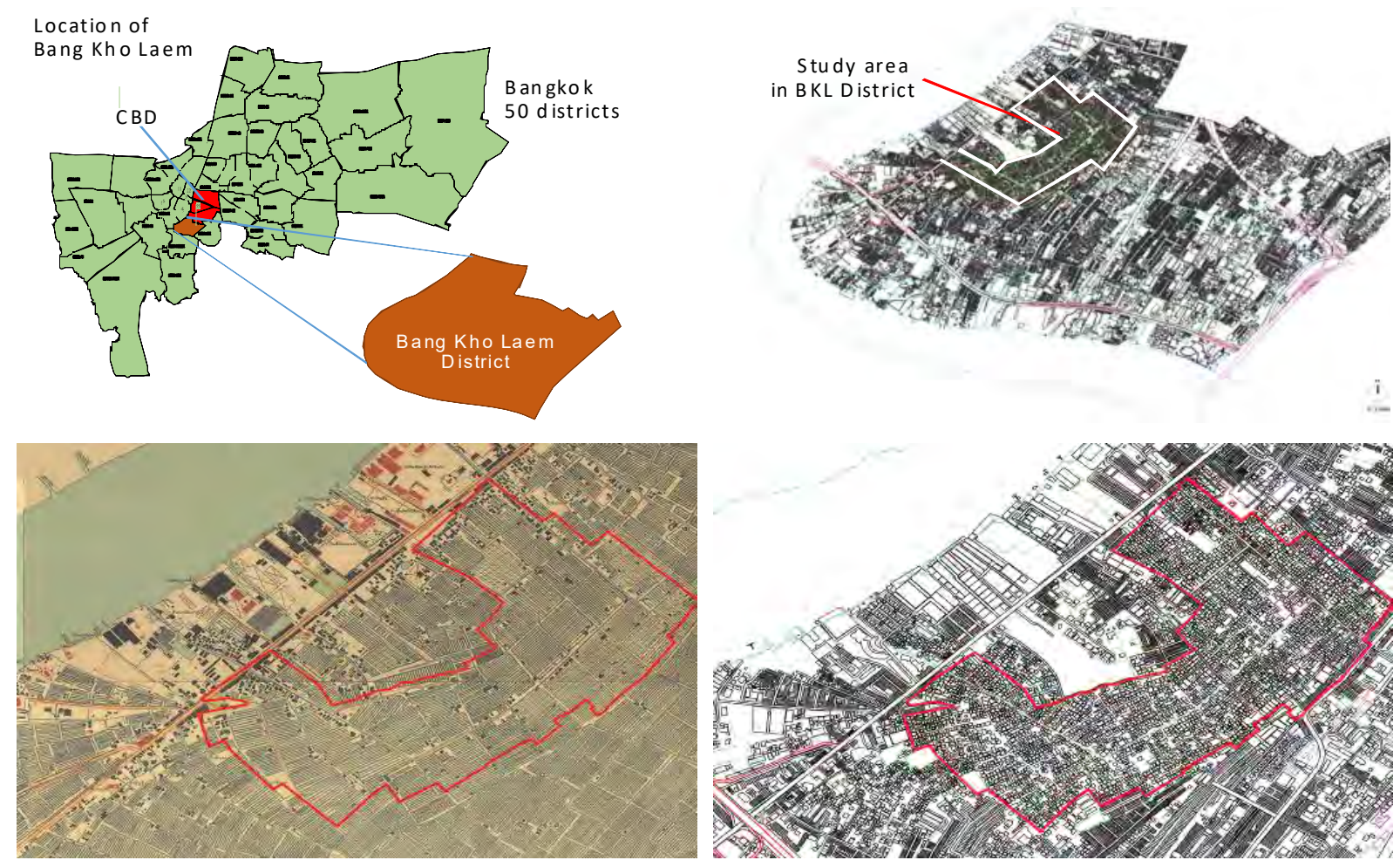

Fig. 3-4 (uppers). The location of the workshop study area, Suan Yai Bang Khwang

Fig. 5-6 (lowers). Comparison of maps illustrating Suan Yai Bang Khwang in 1930 and 2015

Source: (upper and lower right) GIS base map by Department of City Planning,

Bangkok Metropolitan Administration, 2013;

(lower left) The old land use map by Royal Thai Survey Department, circa 1930.

Along with the policy and plan defining the area to be developed under the condition of land use regulation category R-9 following the Ministerial Regulation on the Bangkok Comprehensive Plan 2013 (B.E. 2556) which indicates residential use as the major and commercial and light industry as the minor land uses, whilst allows increase of floor space ratio up to $700 \%$ with fair limit of open space ratio at $4.5 \%$, but without limit of the building height, except those areas along the waterfront, together with the escalation of the development nearby in recent decades, the existing low-rise housing, poor vehicular accessibility, lack of open and greenery spaces, sub-standard public services provision and living with the polluted canal, Suan Yai Bang Khwang hence has been a focus for potential area for the future development of Bangkok.

\section{The workshop format}

The workshop was directed into three sections throughout 7 days, from the workshop commencement, field visit and survey, to group discussion and developing proposals to report to the consortium; all of which were conducted on site visit and in the workshop room at the campus. 

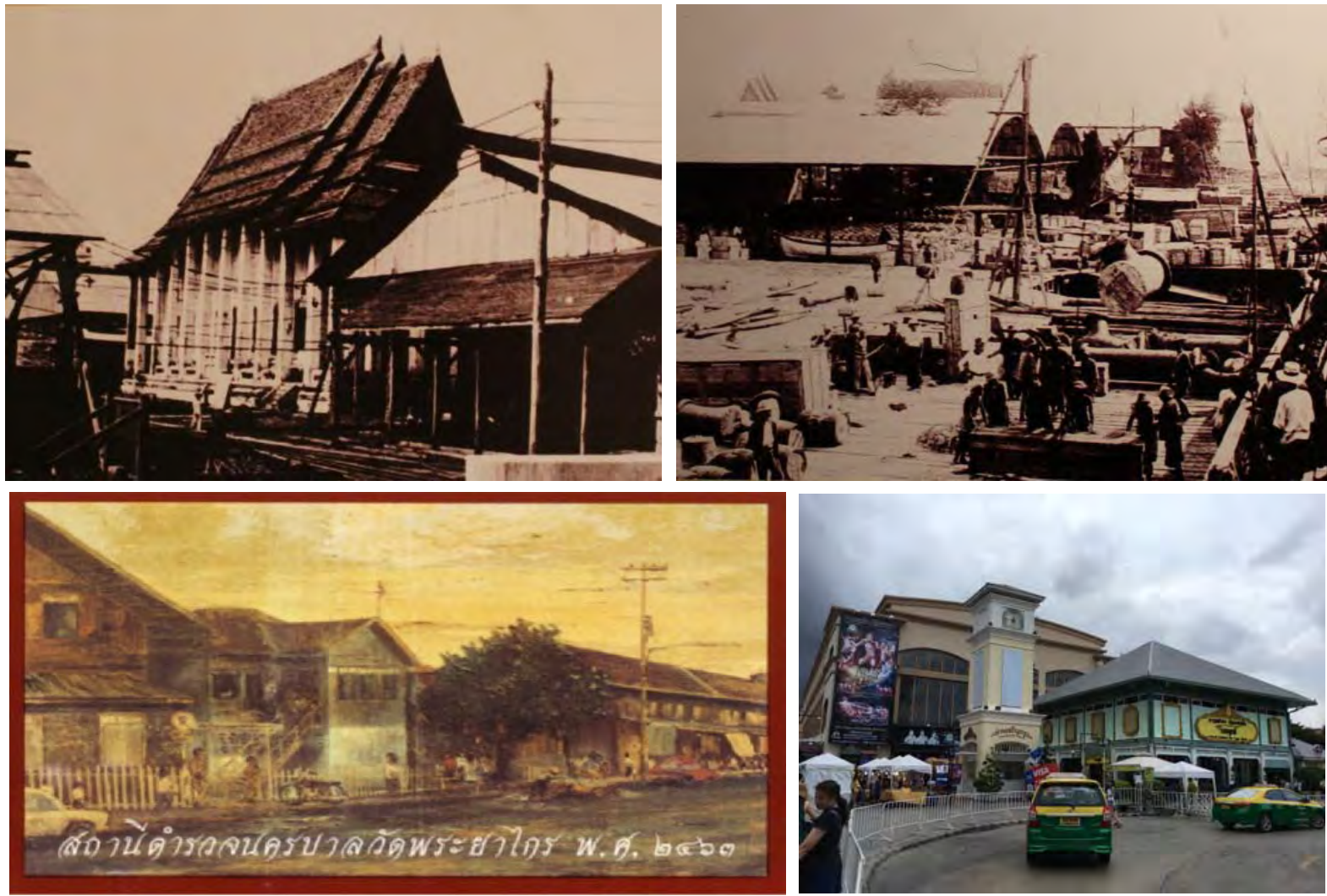

Fig. 7-10 The evolution of land development surrounding Suan Yai Bang Khwang: (upper left) Former Prayakrai Temple, now turned into the Asiatique the Riverfront; (upper right) The East Asiatic Port Warehouse in early $20^{\text {th }}$ century;

(lower left) Former Prayakrai Police Station; (lower right) The present Asiatique the Riverfront Source: (uppers) Baanjompra; (lower left) Watphrayakhrai.metro.police;

(lower right) Yongtanit Pimonsathean, 2017

The first section was undertaken in the first half of day $I$ at the campus by the introduction to the programme and the ideas and experiences shared through country reports by the delegates from the four universities, marking issues and solutions for community development through cases of their home cities. Subsequently, the lecture on urban regeneration in Bangkok, history and the current development circumstances in the study area was given by Assoc Prof Dr Yongtanit Pimonsathean from UDDI.

The second section was set out on the second half of day I to day 3, by which all participants divided into 10 groups conducted the in-depth interviews with key informants of the study area i.e. community leaders, local organisation leaders, etc. on the site visits and collected basic and essential information of the communities' households and livelihoods, and conducted observations for physical appearances of the area. 

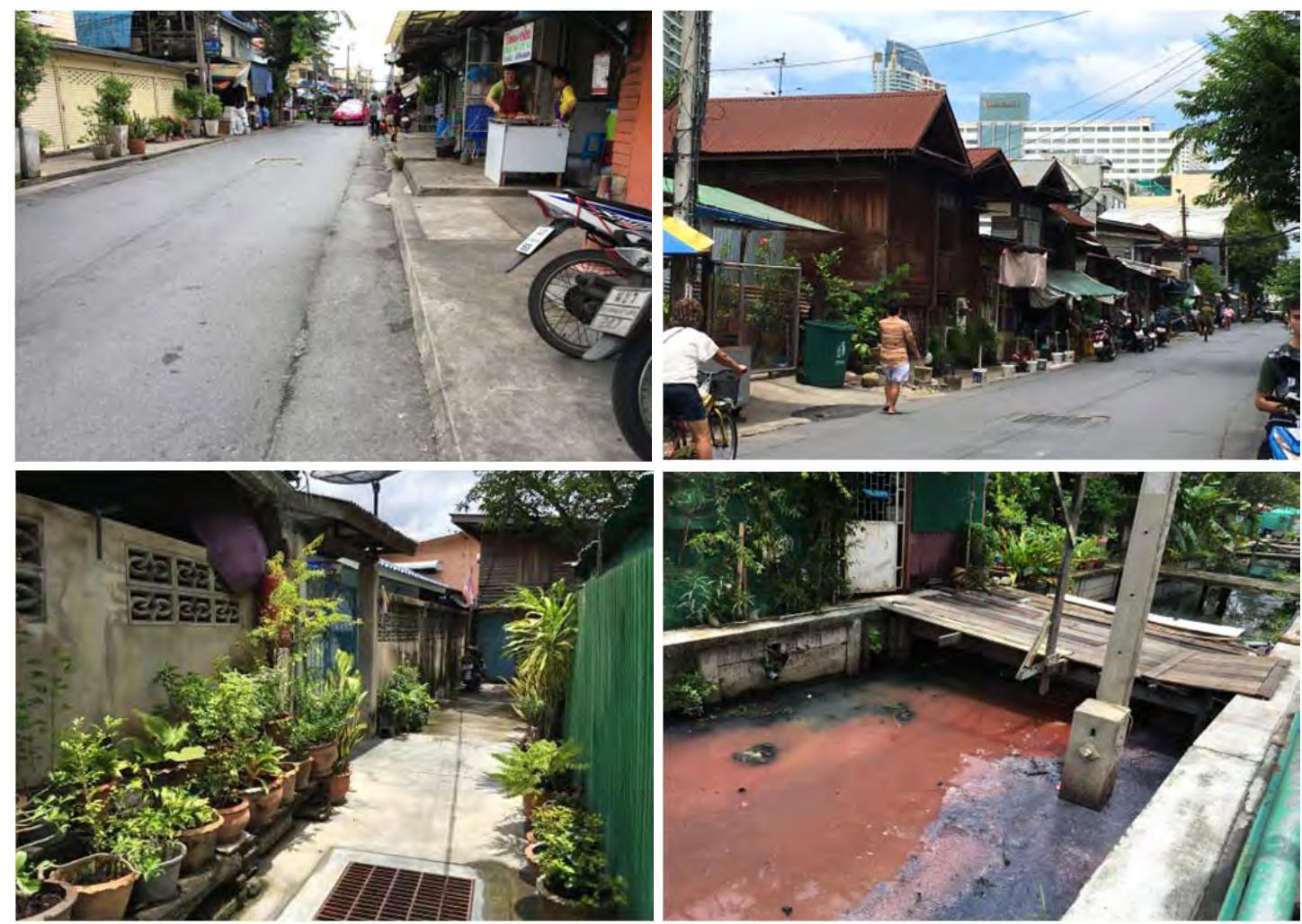

Fig. I I-I4. The circumstances of Suan Yai Bang Khwang:

(upper left) The main road access; (upper right) The densely low-rise housing; (lower left) Poor vehicular accessible; (lower right) The polluted main canal Source: Yongtanit Pimonsathean, 2017.

Besides, on day 2 all participants visited and attended a lecture by TCDC and the guest lecturer, Mr Thanan Lilaonitkul, the manager of Creative District Bangkok, on "CoCreation Development" at Thailand Creative and Design Center (TCDC), Bangkok Office, to derive the ideas of the creative development and shared experiences from the cases applied. For the third section, in the evening of day 3 to day 5 all participants returned to the campus and sitting together doing group discussion, sharing materials and ideas from the site visits and data collection to consolidate identifying the negative and positive assets of the study area, after that, developed ideas to propose solutions for community development particularly concerning holistic approach by means of integrative involving stakeholders under their basis of needs and resources availability. The group work was conducted under the supervision of all the workshop instructors in the format of desk critics and panels throughout days and nights.

Towards the students' proposals on the study area regeneration, the final product of the work was presented through slides on day 6 at the workshop final event and debriefing, and following the supervisors' instructions prepared posters in the format of sets of 25 creative idea cards by each group of the students in order to be presented at the $8^{\text {th }}$ IACSC on the following day. The final proposals introducing urban regeneration into Suan Yai Bang Khwang ranged from enhancing mobility and accessibility, community betterment, housing development, and disaster prevention, connecting the residents and the main canal, boosting the local economy, improving the community development, tidying spaces and creating green space, to creating local street markets into the area. 


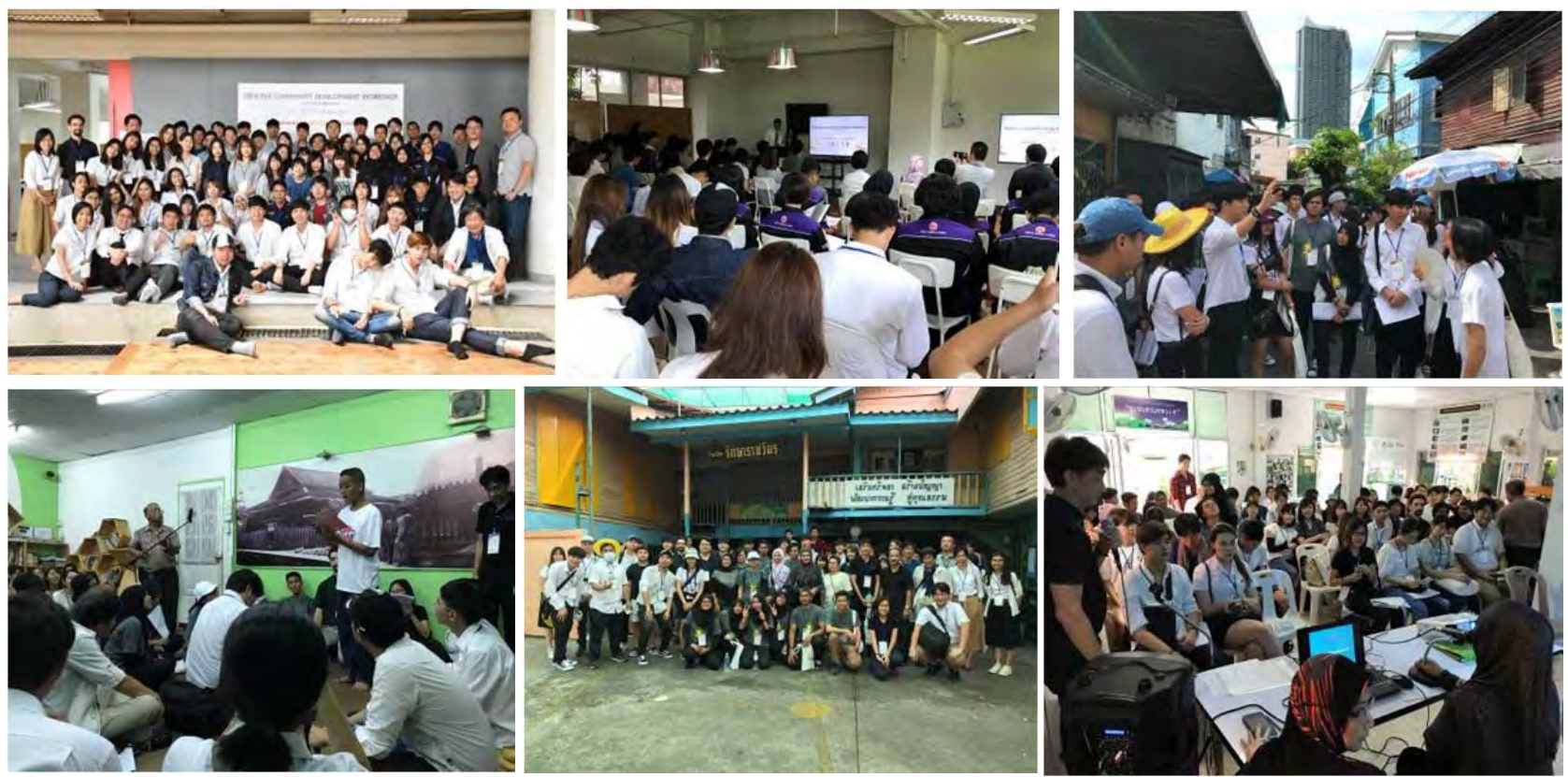

Fig 15-I8 (upper left and middle). The workshop opening ceremony, introduction and lectures; (upper right) The workshop participants on field survey along the reconnaissance route; (lower left and middle) Suan Luang I Community welcoming the workshop participants on the site visit;

(lower right) The community leader of Suan Luang I Community was presenting the successes and lessons learnt from the community initiative programme

Source: (upper left) Naoyuki Kuniyoshi, 2017; (upper middle and right; lowers) Jarunee Pimonsathean, 2017
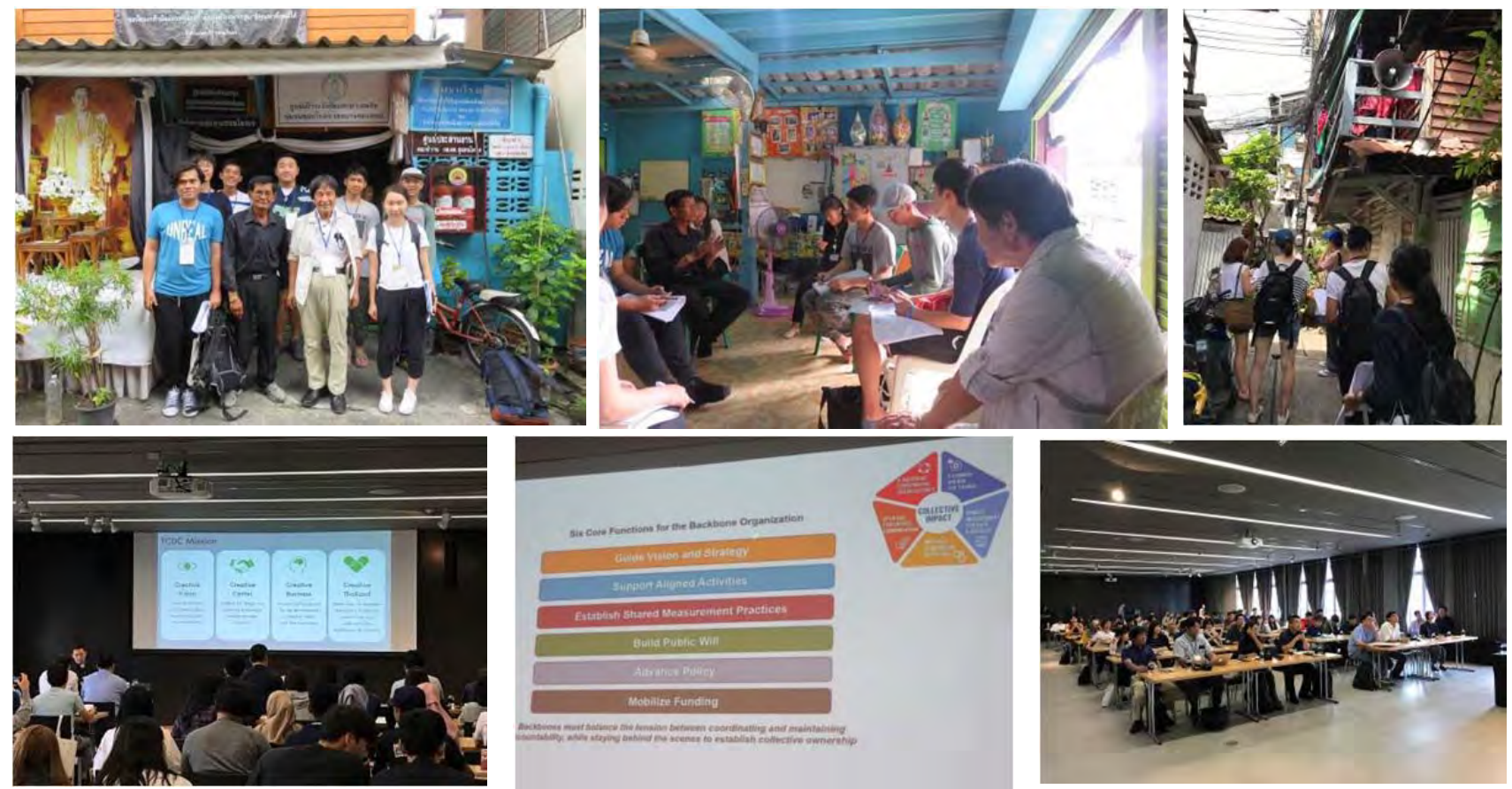

Fig. 19-24 (uppers). A workshop participant team visited a community in the study area and conducted in-depth interview with the community leader;

(lowers) The workshop participants visited and attended the lecture on "Co-creation Development" at Thailand Creative and Design Center (TCDC) at the Old Head Quarter of Post Office Building

Source: Naoyuki Kuniyoshi, 2017 

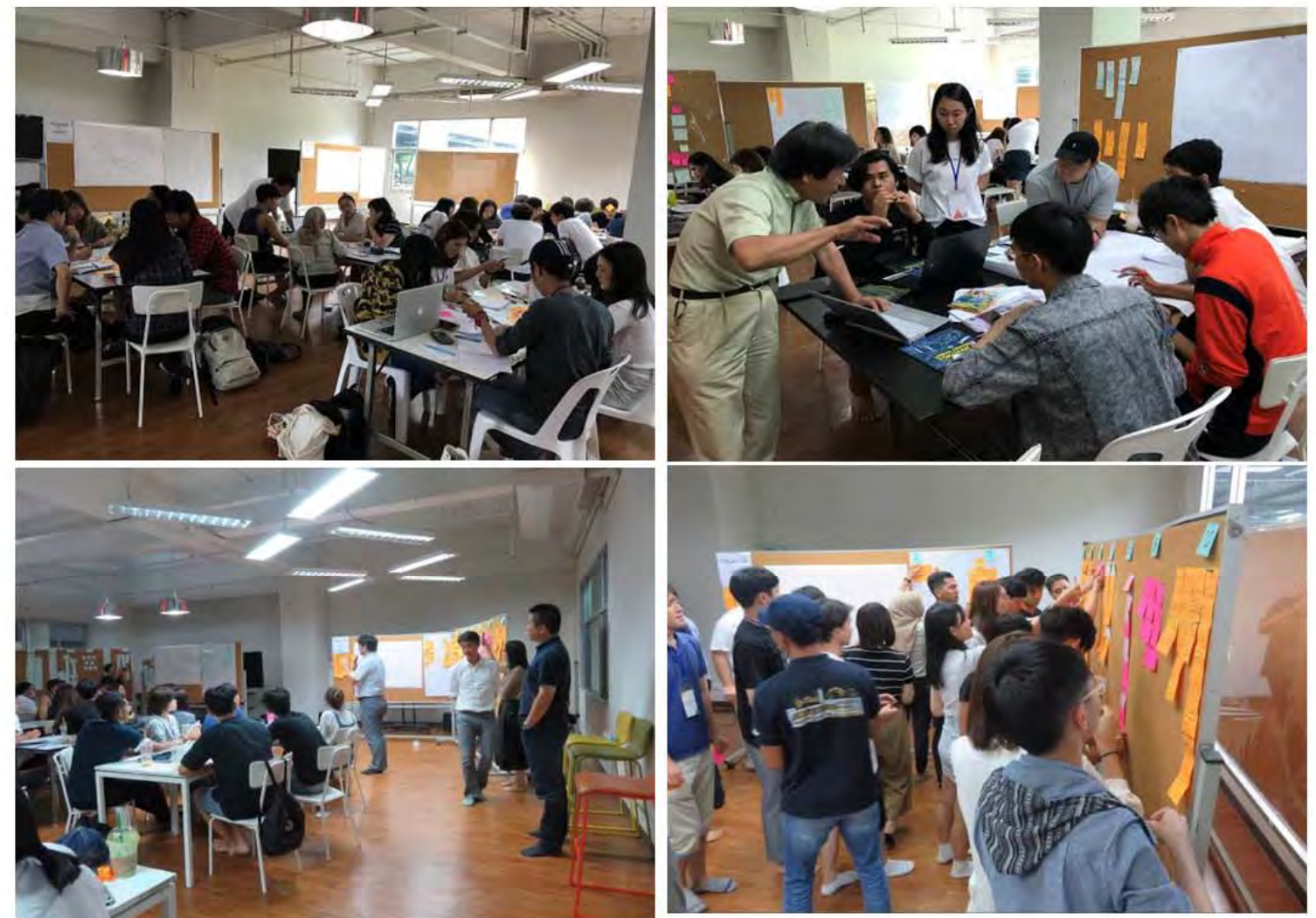

Fig 25-28. Group discussion and instructors' supervisions at Thammasat University after the study site visits and data collection, for identifying positive and negative assets of the community Source: (uppers and lower left) Jarunee Pimonsathean, 2017; (lower right) Naoyuki Kuniyoshi, 2017
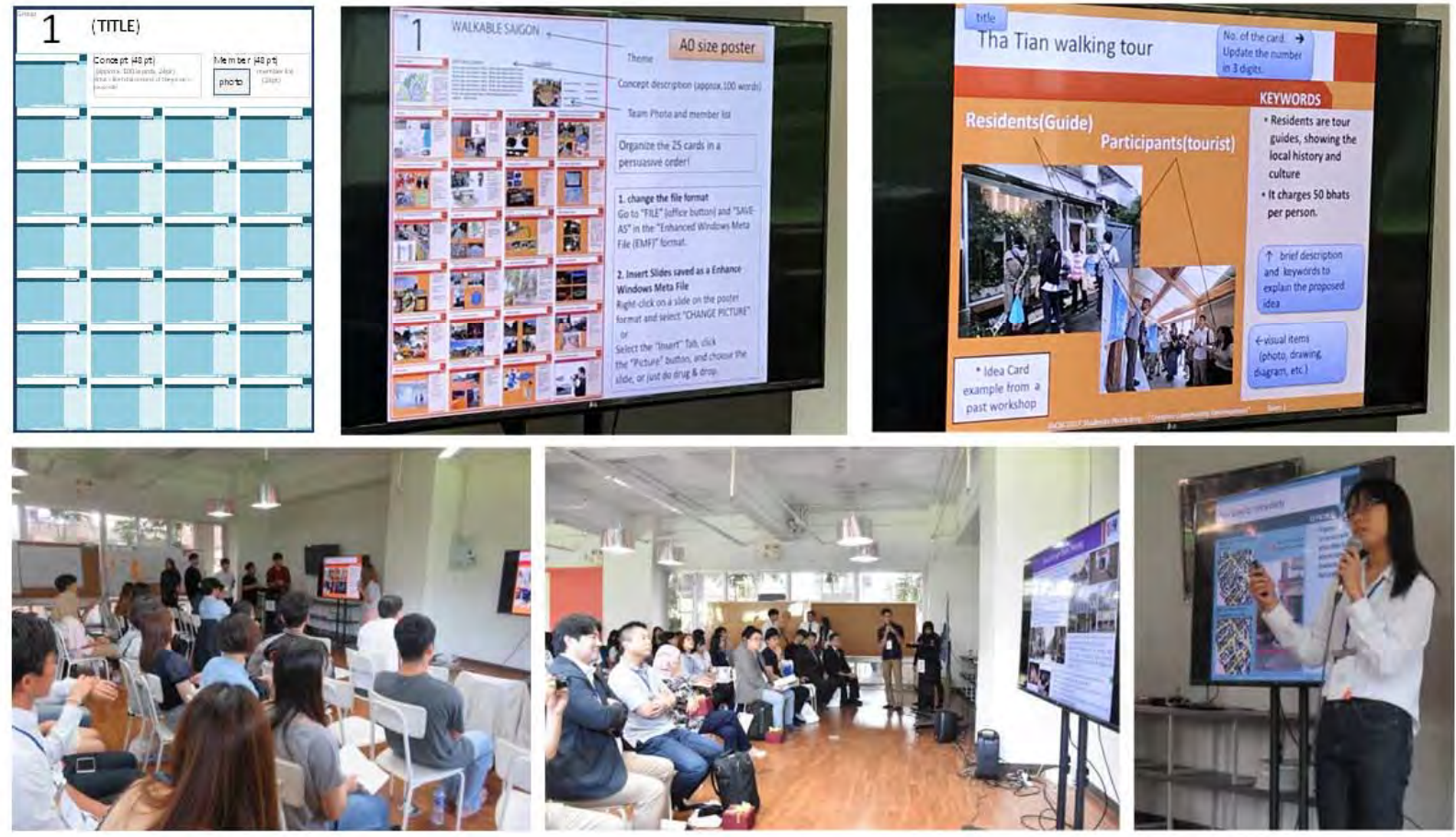

Fig 29-34 (uppers). The 25 idea card poster format; (lowers) The workshop final event and debriefing Source: (upper left) Mariko Fujioka, 2017; (upper middle and right) Jarunee Pimonsathean, 2017;

(lowers) Naoyuki Kuniyoshi, 2017

I 8 | The Journal of Public Space, 2(4), 2017| ISSN 2206-9658

(c) Queensland University of Technology 


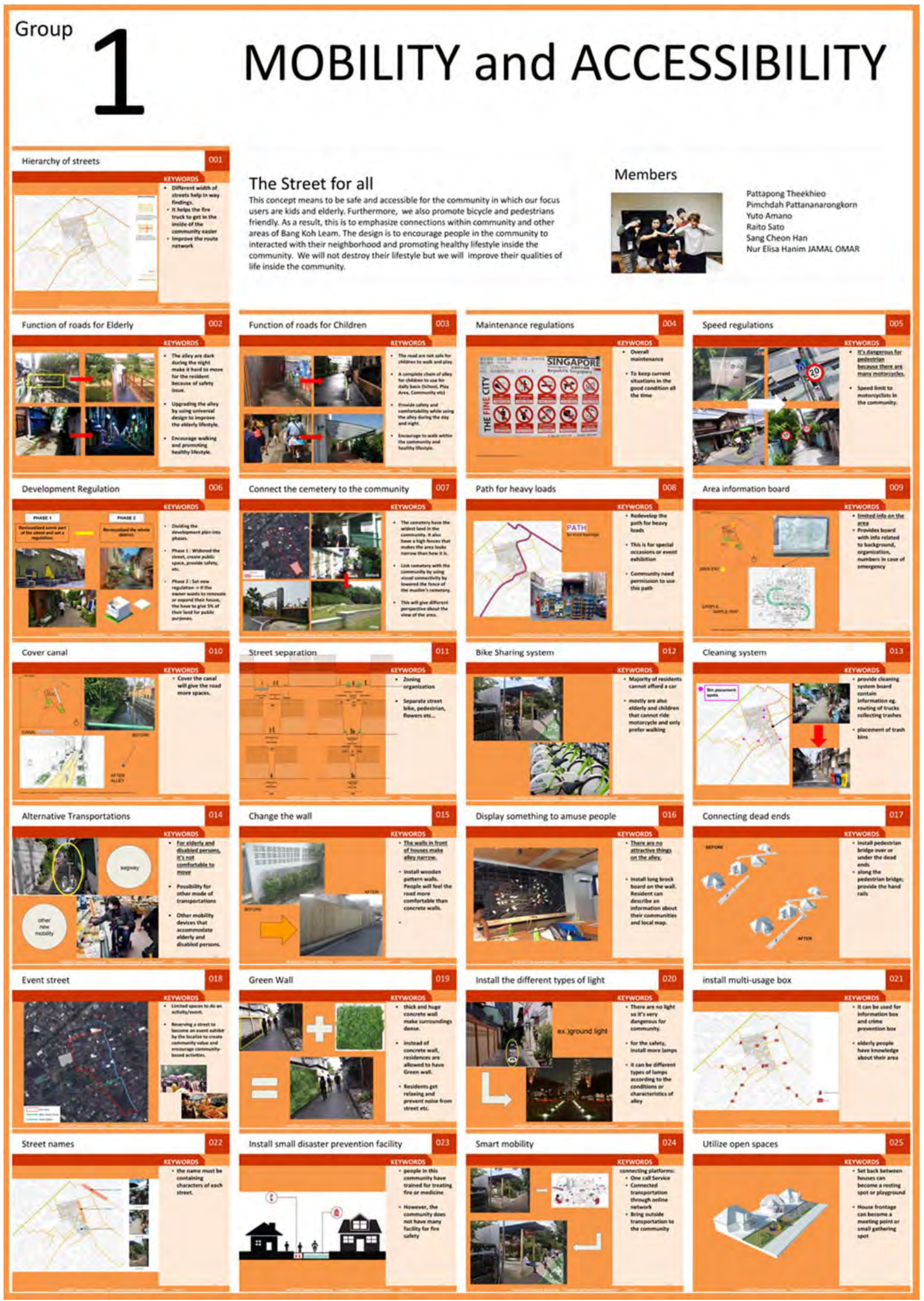

Fig. 35. The 25 idea card poster from Group I. Source: IACSC, 2017 


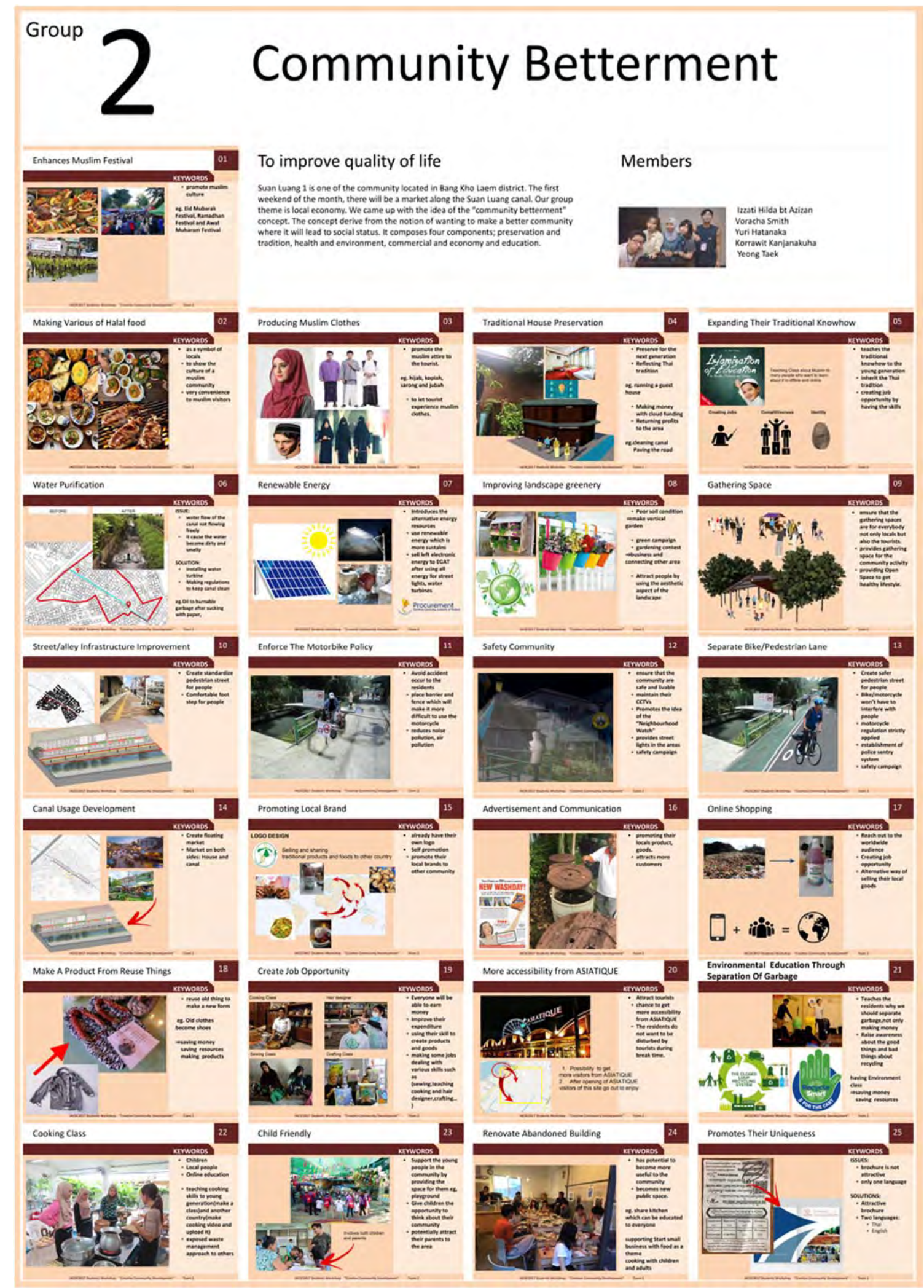

Fig. 36. The 25 idea card poster from Group 2. Source: IACSC, 2017

I 20 | The Journal of Public Space, 2(4), 2017| ISSN 2206-9658

(c) Queensland University of Technology 


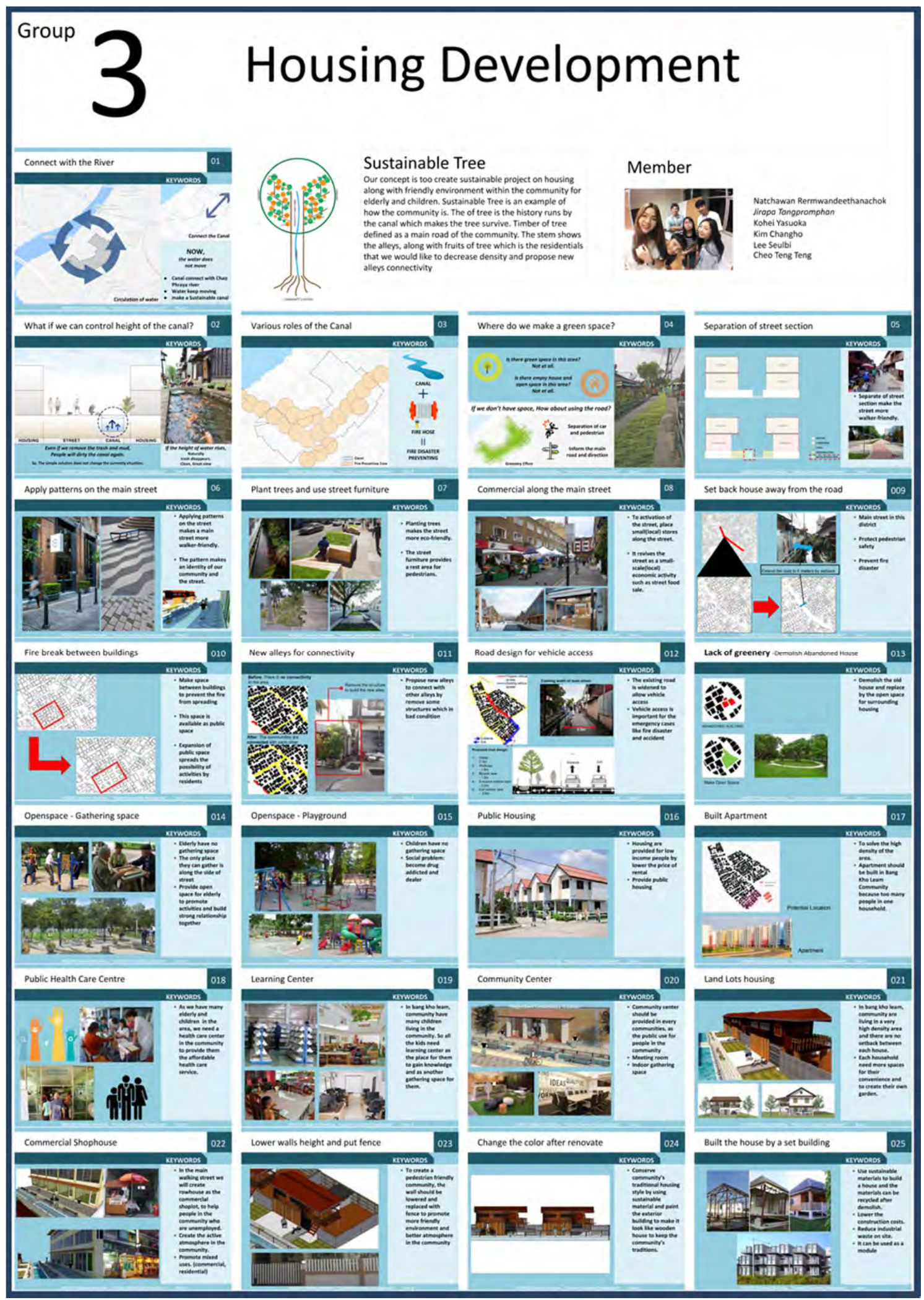

Fig. 37. The 25 idea card poster from Group 3. Source: IACSC, 2017 


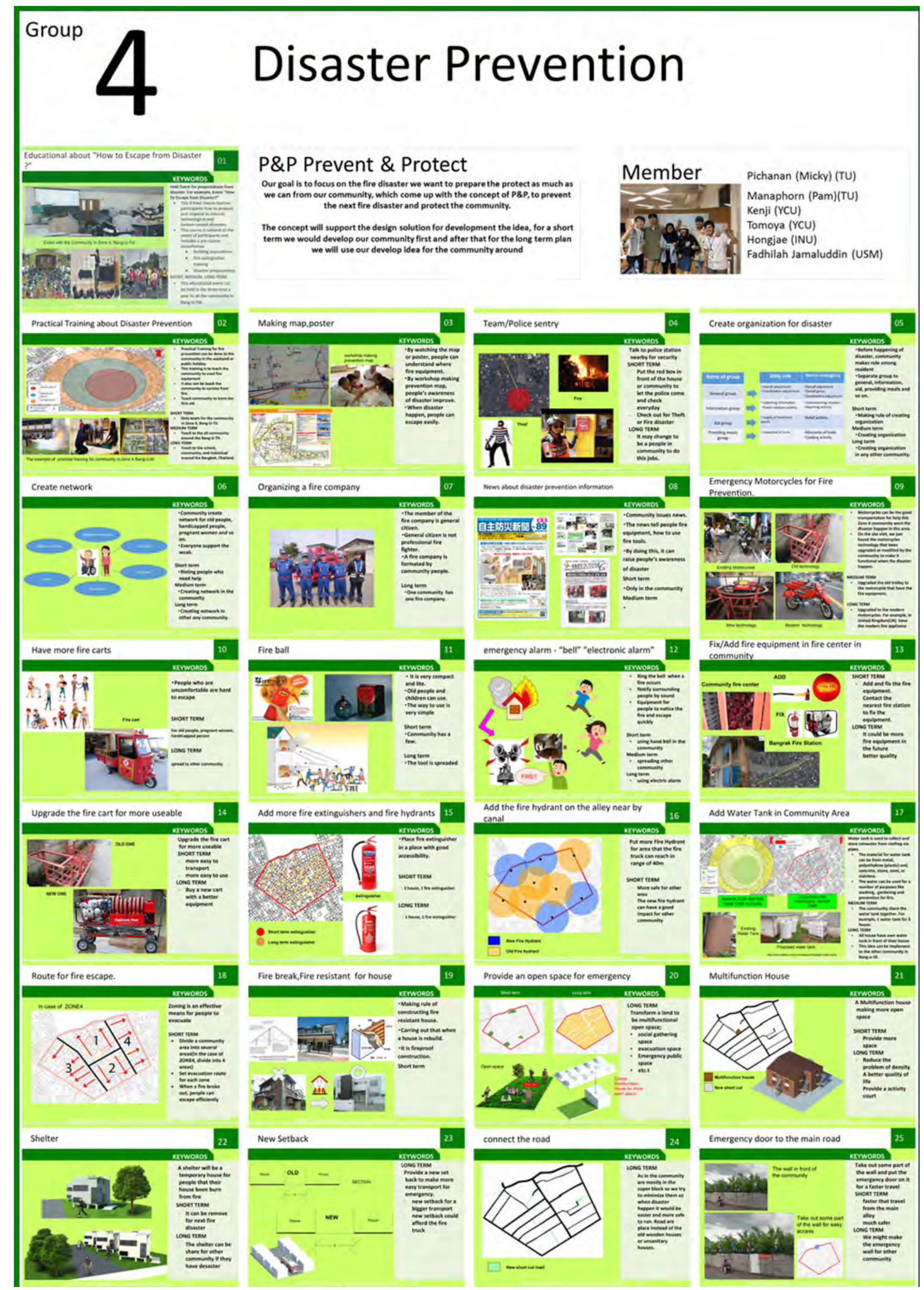

Fig. 38. The 25 idea card poster from Group 4. Source: IACSC, 2017

I 22 | The Journal of Public Space, 2(4), 20I7| ISSN 2206-9658

(c) Queensland University of Technology 


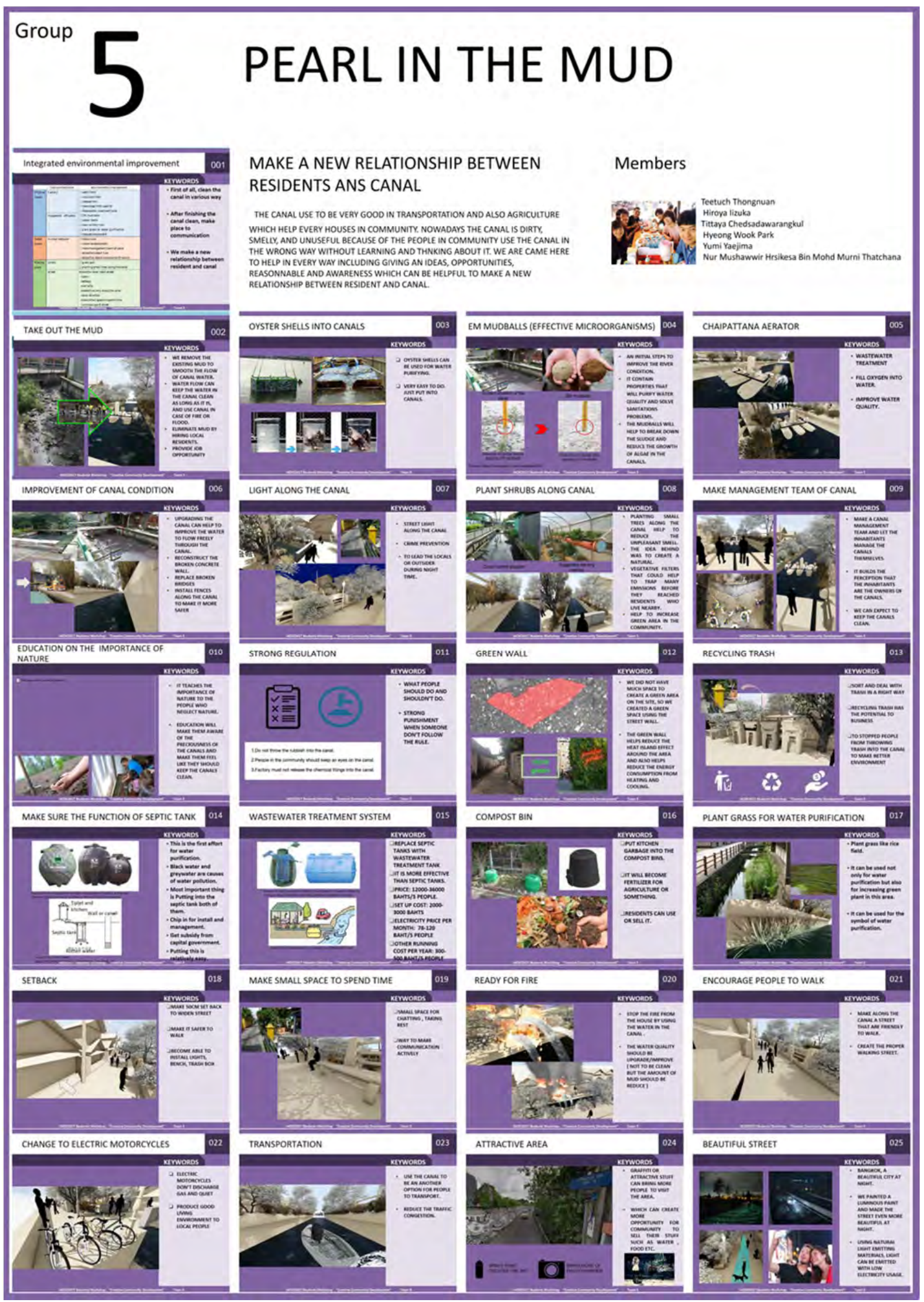

Fig. 39. The 25 idea card poster from Group 5. Source: IACSC, 2017 


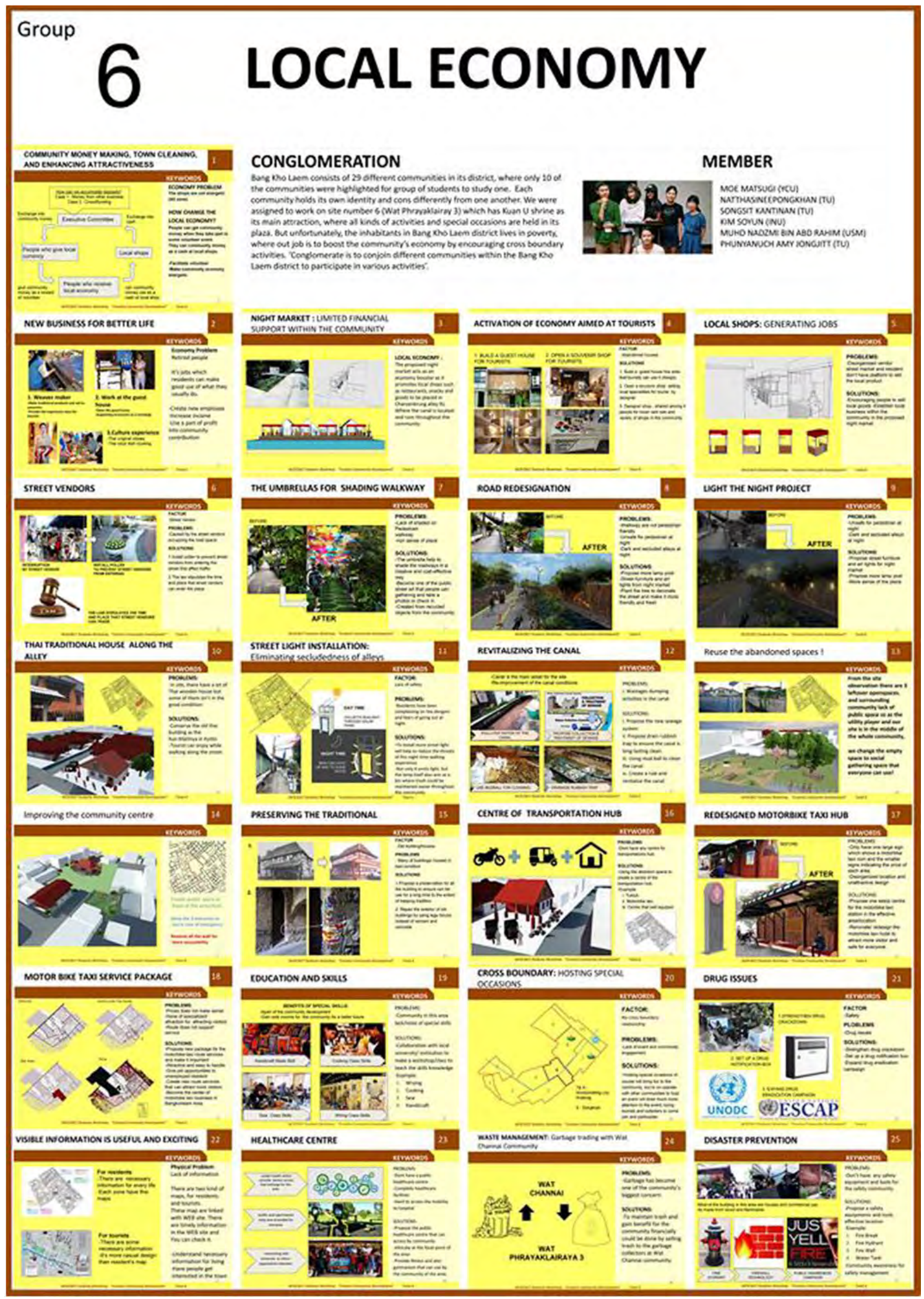

Fig. 40. The 25 idea card poster from Group 6. Source: IACSC, 2017

I24 | The Journal of Public Space, 2(4), 2017| ISSN 2206-9658

(c) Queensland University of Technology 


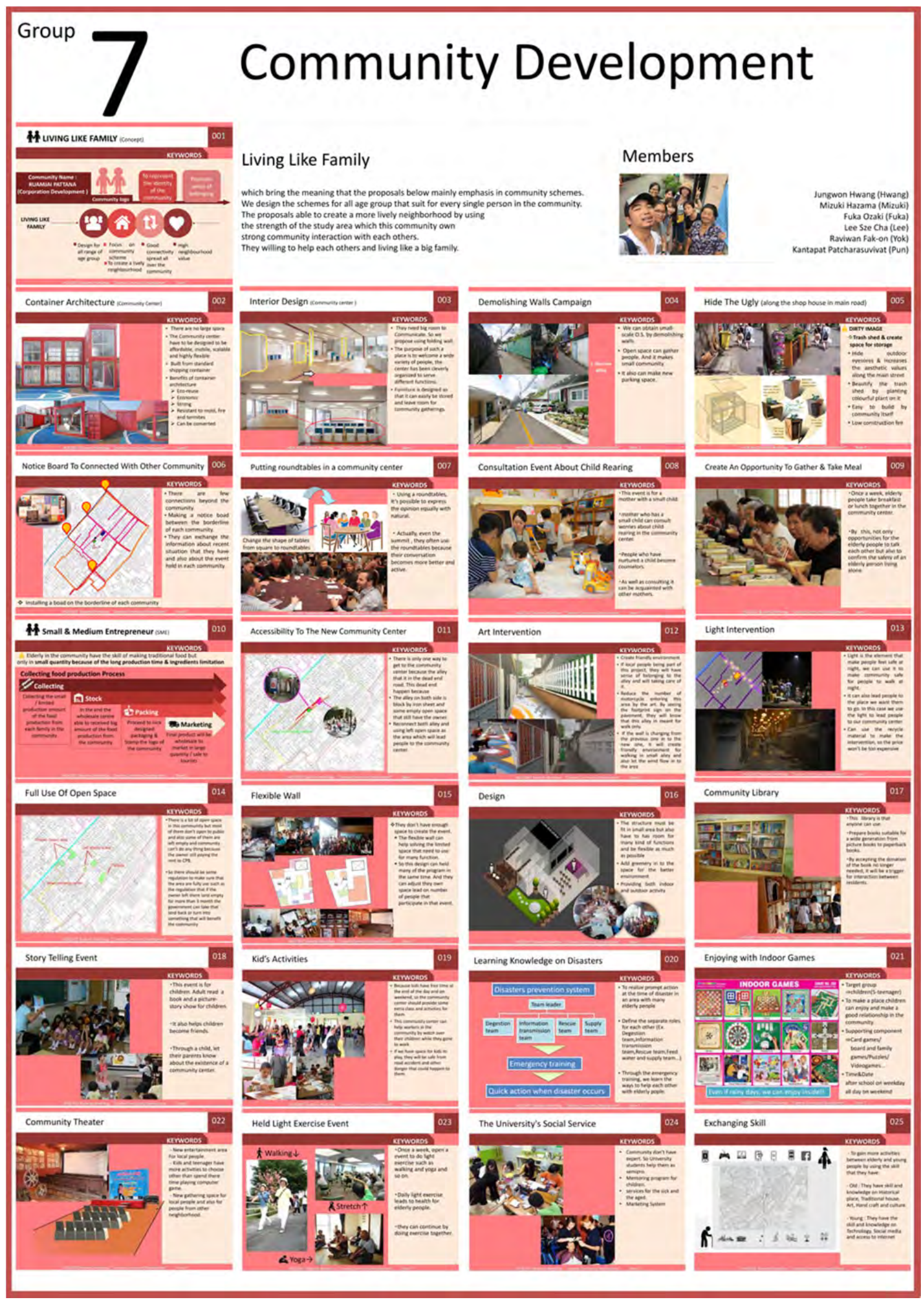

Fig. 4I. The 25 idea card poster from Group 7. Source: IACSC, 2017 


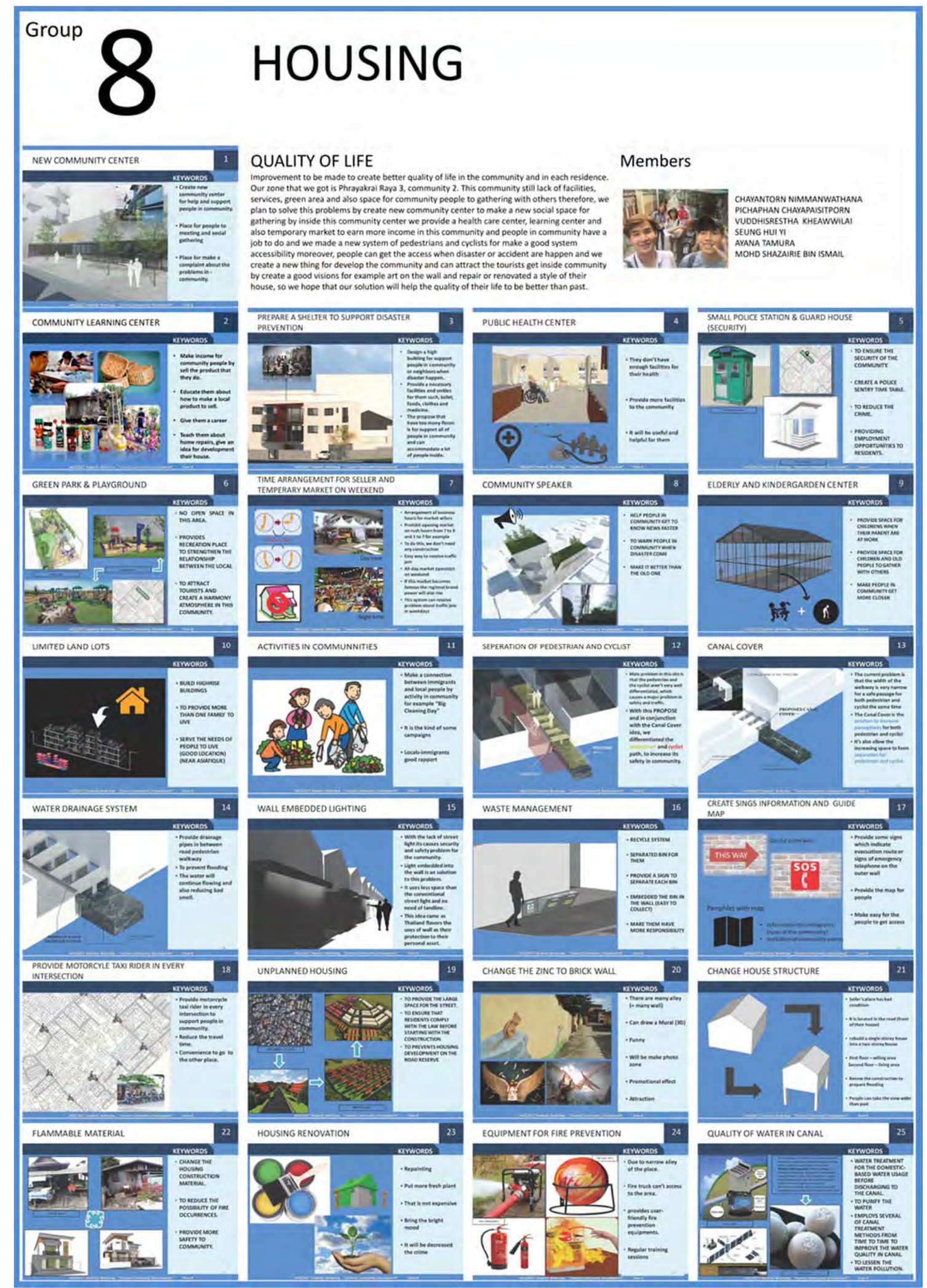

Fig. 42. The 25 idea card poster from Group 8. Source: IACSC, 2017

I 26 | The Journal of Public Space, 2(4), 2017 | ISSN 2206-9658

(c) Queensland University of Technology 


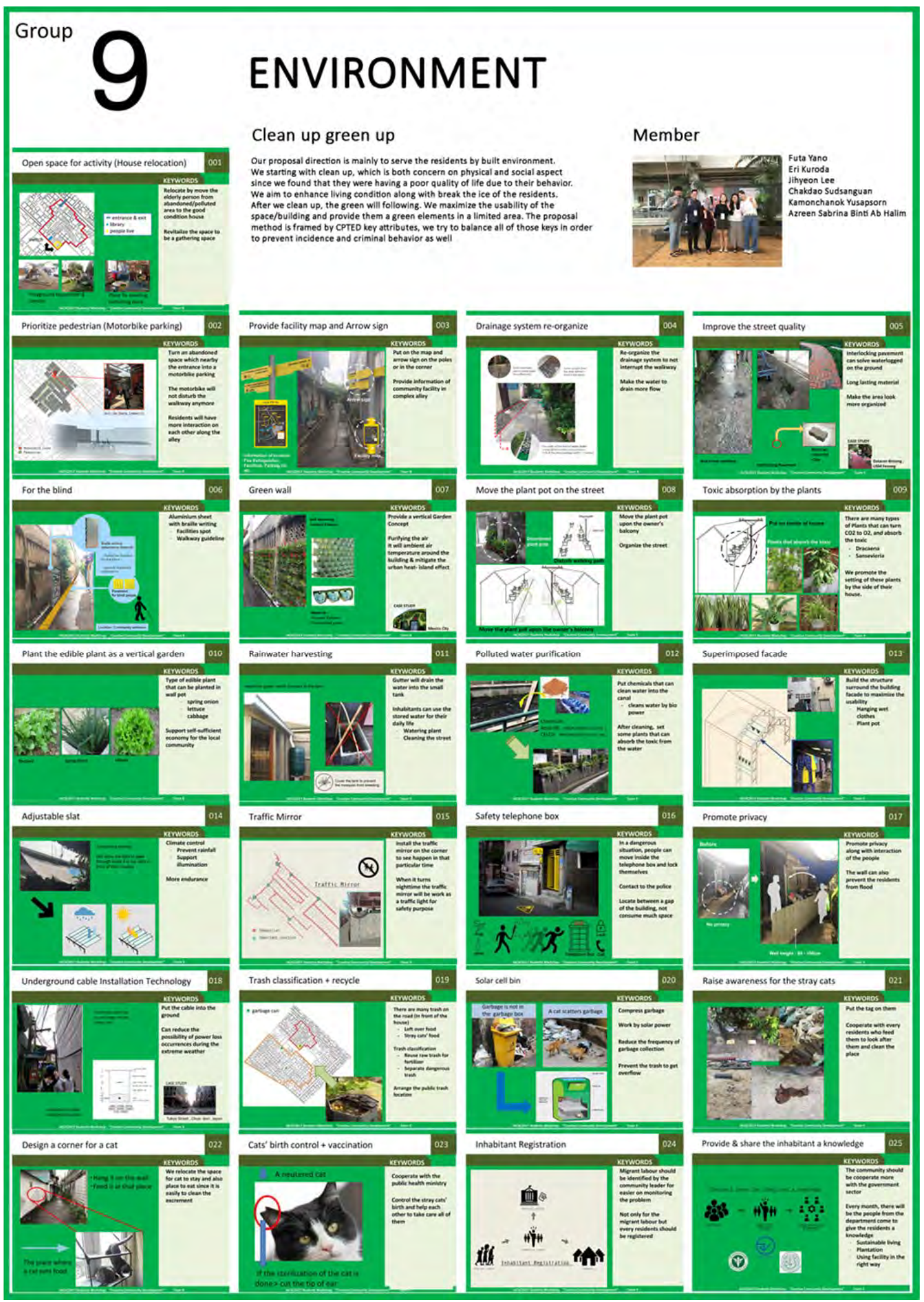

Fig. 43. The 25 idea card poster from Group 9. Source: IACSC, 2017 


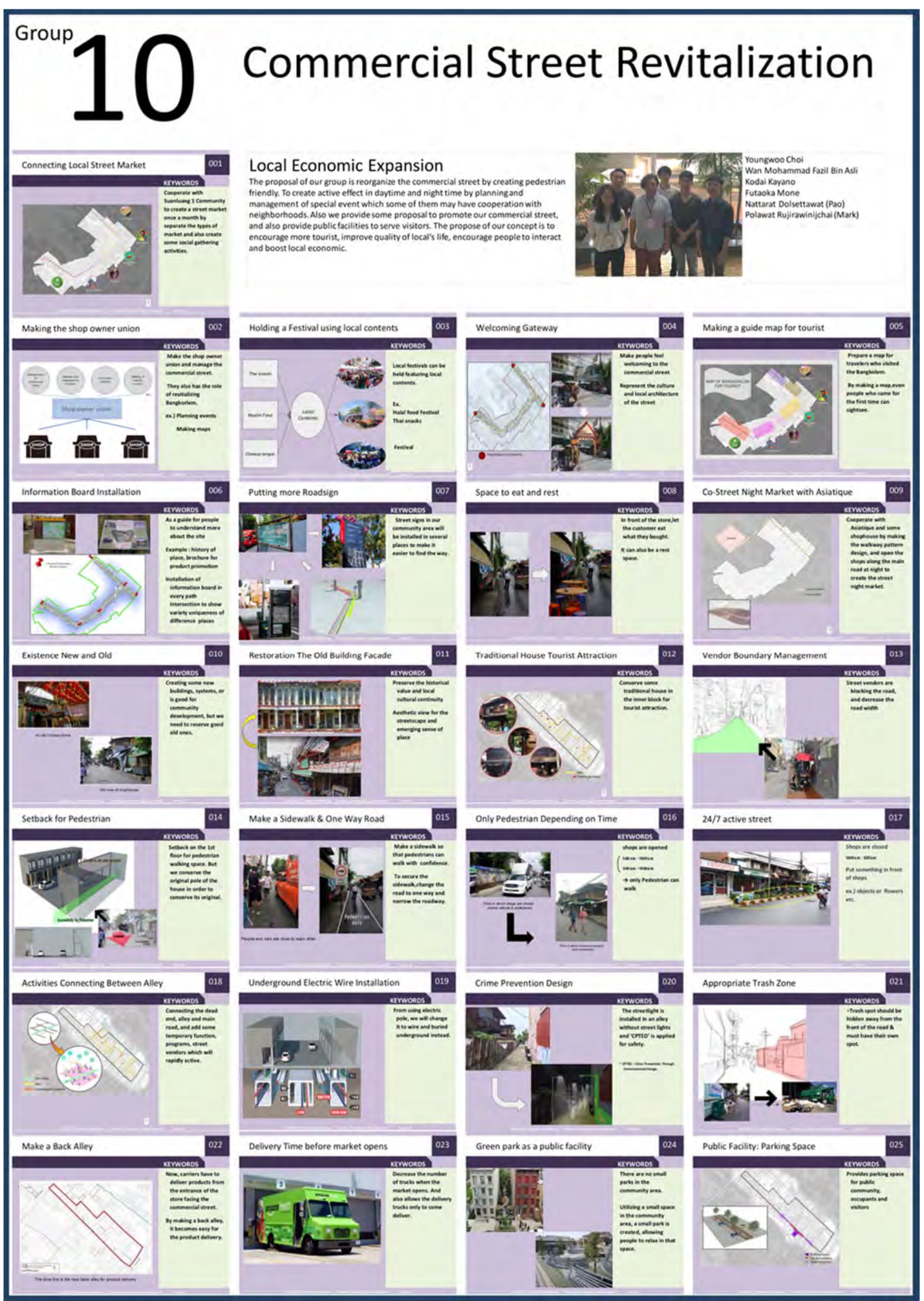

Fig. 44. The 25 idea card poster from Group 10. Source: IACSC, 2017

I 28 | The Journal of Public Space, 2(4), 2017 | ISSN 2206-9658

(c) Queensland University of Technology 
The final proposals were presented to the IACSC at the poster session at its $8^{\text {th }}$ General Assembly and Symposium, at Thammasat University, Rangsit Campus, on II September 2017. Although there were difficulties for students to setting ideas and proposals under the limited time of the workshop, it successfully provided working together arena among the international students, and between the students and the local communities for the benefit of their mutual learning and understanding. In addition, the contribution suggested various ideas towards livable and sustainable towns and cities can be extended for further individual studies or researches following the interests of the workshop participants as well as the public, as some of the participants tended to be interested in. Afterwards, back to the UD326 Urban Regeneration studio till the end of the semester which lasted until early of December 2017, the area regeneration schemes and design proposals were brought to be developed more in details to elaborately address the local needs and aspirations, with full consideration on the limitations of the current city regulations and orders and the opportunities and impacts to the city economy wide.
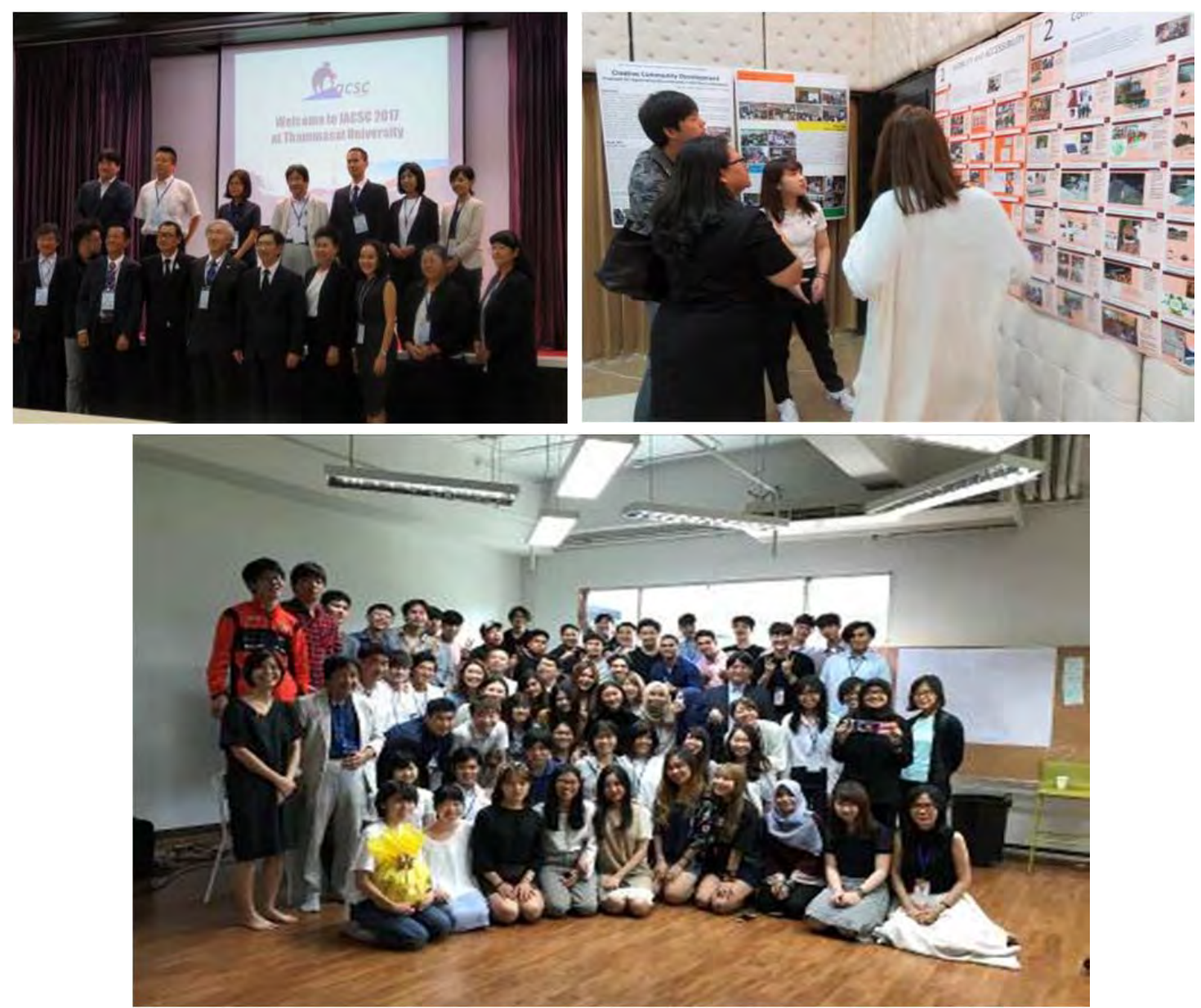

Fig. 45. The $8^{\text {th }}$ IACSC General Assembly and Symposium at Thammasat University Figure 46 The Creative Community Development final proposals presented at the poster session of the $8^{\text {th }}$ IACSC General Assembly and Symposium Figure 47 The final event of the Creative Community Development Workshop Source: Naoyuki Kuniyoshi, 2017 


\section{Acknowledgments}

The author wish to thank Associate Professor Dr Yongtanit Pimonsathean, Prof. Naoyuki Kuniyoshi, Associate Professor Dr Mariko Fujioka, Ms Hansa Srilertchaipanij and UDDI Year 3 students enrolled I/20I7 for their resources supporting the contents and illustrations for this article.

\section{To cite this article:}

Pimonsathean, J. (2017). Creative Community Development. From urban design studio to international collaborative workshop. The Journal of Public Space, 2(4), III-I30. DOI: 10.5204/jps.v2i4. 146

This article has been accepted for publication in The Journal of Public Space. Please see the Editorial Policies under the 'About' section of the journal website for further information.

c) (i) (3) This work is licensed under a Creative Commons Attribution - Non Commercial 4.0 International License - https://creativecommons.org/licenses/by-nc/4.0/ 